F. Reprod. Fert. (1973) 33, 367-377

\title{
EFFECTS OF SUCKLING AND TIME TO MATING AFTER PARTURITION ON REPRODUCTION IN THE DOMESTIC RABBIT
}

\author{
G. R. FOXCROFT* AND H. HASNAIN $\dagger$ \\ Department of Physiology and Environmental Studies, \\ University of Nottingham School of Agriculture, \\ Sutton Bonington, Loughborough, Leicestershire
}

(Received 4th April 1972)

Summary. The occurrence of mating, ovulation and fertilization of ova was established in Large Albino (LA) and Dutch Belted (DB) does following parturition. The effects of increasing intervals to mating, and presence or absence of suckling in the case of the LA does, on the above parameters of fertility were determined.

No depression in successful mating was found in lactating does compared to weaned controls in the early period after parturition. A significant increase in induced ovulation with increased time to mating was established for DB but not for LA does. In the LA animals, suckling significantly depressed the ovulation response to mating.

The percentage of successfully fertilized ova was significantly lower in some of the post-partum mated DB rabbits compared to controls but no treatment effects on fertilization of ova were established for the LA does.

Patterns of ovarian and uterine involution were observed in the LA does. Ovarian involution was characterized both by rapid regression of corpora albicantia and by a decrease in follicular development. This decrease in follicular development suggests a decrease in pituitary gonadotrophin secretion following parturition, and the resultant decline in follicular oestrogens may be responsible for the formation of smaller CL with increased time to mating after parturition.

\section{INTRODUCTION}

Little precise information is available on the physiology and reproductive performance of the domestic rabbit following parturition. Hammond (1925) reported that oestrus was suppressed in lactating does after the 12th day post partum, and that the degree of uterine and ovarian involution was greater than that observed in non-suckling animals. Reduced fertility in the case of lactating does was possibly due to inadequate nutrition in this early study, resulting

* Present address: Animal Genetics Laboratory, Department of Animal Science, University of Illinois College of Agriculture, Urbana, Illinois 61801, U.S.A.

$\dagger$ Present address: West Pakistan Veterinary Research Institute, Harike Road, Lahore, Cantt-13, Pakistan. 
in reduced FSH stimulation of follicular development and hence also in luteal regression in does that had ovulated (Adams, 1967). Yaschine, Mena \& Beyer (1967) observed occasional sexual activity in lactating rabbits.

Harned \& Casida (1969) reported that significantly fewer primiparous does mated on Day 4 post partum compared to Day 1, and that suckling reduced the ovulation response to these matings; neither of these effects was found for multiparous does. In both groups of does, suckling significantly reduced the number of large follicles in the ovaries. A marked post-partum oestrus was reported by Beyer \& Rivaud (1969) in the lactating rabbit, followed by a rapid decline to low levels of sexual activity throughout the remainder of lactation. Of fifty-five does mated during lactation, only seven (12\%) carried successful pregnancies.

A recent study by Breed \& Hilliard (1970) in the rabbit examined the effects of lactation on ovarian function. The patterns of ovarian and uterine involution were described and rapid regression of the CL of the previous pregnancy was observed. Increasing time after parturition was found to have no significant effect on the size of the largest follicle measured.

In view of the considerable interest in establishing pregnancy concurrent with lactation in domestic animals, the present experiments were undertaken to examine the sequence of changes in the fertility and sexual activity of the domestic rabbit following parturition. Initially, an investigation was confined to groups of suckling does. Subsequently, it was considered important to determine the relative influence of (a) the suckling stimulus and (b) the time after parturition at mating, on the patterns of reproductive behaviour previously established.

\section{MATERIALS AND METHODS}

\section{Experiment 1}

Animals. Dutch Belted (DB) primiparous rabbits from the University's closed colony were used throughout. Animals were individually caged and had unrestricted access to a supply of water and a pelleted ration containing approximately $17 \%$ protein and $87 \%$ dry matter supplemented with minerals and vitamins to meet normal maintenance requirements. A constant $12 \mathrm{hr}$ light/12 $\mathrm{hr}$ dark lighting regimen was maintained. Before kindling, does were moved to larger cages containing nest boxes, and a quantity of hay or straw was provided to facilitate nest building. At the time of allocation to experimental groups, the does weighed 2 to $3 \mathrm{~kg}$.

Sexual behaviour. Does were tested for mating with mature fertile bucks at specific times after parturition. On the day of testing, the does were placed with one or more bucks in an attempt to procure successful matings and, if necessary, were tested both in the morning and afternoon. A doe was recorded as mating only after mounting and successful intromission had been clearly observed. Does refusing to mate on the day of testing were not subsequently used in the experiment in order to remove any conditioning effect due to contact with the bucks. To prevent any bias of results due to seasonal effects, animals were allocated randomly to all experimental groups during the year. 
All does suckled litters of five young, the litters being adjusted accordingly soon after parturition. The effect of time post partum was established by testing groups of does for mating on the day of parturition (Day 0 ) and on the 3rd, 6th, 9 th and 12th days after parturition, with a further control group mated following weaning at 21 days post partum. Except for the control group, in which six successfully mated does were used, testing was continued at each time until twenty does/group had been successfully mated. Data relating to ovulation were obtained from all these does, whereas data on subsequent fertilization were obtained from ten mated animals in each group; the remaining ten does were used in a study of embryonic mortality 9 days post coitum, which is not reported in this paper.

Fertility. Two parameters of fertility were used in this experiment: (1) the occurrence of ovulation following mating; (2) the fertilization of tubal ova. In this study, ten does in each group were killed 2 days post coitum, and the uterus, Fallopian tubes and ovaries were removed and dissected free of surrounding adipose and mesenteric tissue. The ovaries and uteri were weighed and, following examination, were stored in $10 \%$ formol saline. The numbers of CL and Graafian follicles in each ovary were recorded (further data on ovulation were subsequently obtained from does killed 9 days post coitum).

When the presence of CL indicated that ovulation had occurred, the Fallopian tubes were flushed with a small volume of isotonic saline and the recovered ova were examined under a binocular dissecting microscope for the presence of fertilization. This was assessed on the basis of evidence that cleavage had been initiated even if subsequent degeneration had occurred. When failure of fertilization was recorded, ova were mounted on glass microscope slides and examined by phase contrast microscopy for the presence or absence of spermatozoa in the ovum and its surrounding structures, in order to establish whether failure of sperm transport or of penetration of the ovum could have been responsible.

\section{Experiment 2}

Animals. Throughout this experiment, Large Albino (LA) rabbits from the University's closed colony were used. Caging and management were as described for Exp. 1 and does weighed 2.8 to $3.2 \mathrm{~kg}$ when allocated to experimental groups at the time of their second parturition.

Sexual behaviour. The mating response of the does was established, using the testing procedures described for the first experiment.

To determine the effect of time of mating post partum, groups of does were tested for mating on the 3rd,6th, 9th and 12th days after parturition with control groups mated at 30 days post partum following weaning at 28 days if necessary. To establish the effects of suckling at each of these times, groups of does had their litters removed completely (non-suckling) or adjusted to six young per doe (suckling) on the day of parturition. The day of parturition was again designated Day 0 . Sufficient does were tested in each group to provide ten successfully mated animals for subsequent studies.

Fertility. Estimates of fertility were made for all mated does and all procedures used in these studies were as described for the first experiment. 
Uterine and ovarian histology. Histological sections of the uterus and ovary were prepared to establish changes occurring during the post-partum period. Samples of fixed uterine material were taken from the mid-uterine horn region and cut transversely at $7 \mu \mathrm{m}$.

Ovarian changes were studied histologically in the Day- 3 and Day-9 suckling and non-suckling groups, and in the Day-6, Day-12 and control suckling groups of does. Sections were cut at $7 \mu \mathrm{m}$ and every seventh section was mounted to obtain serial sections at approximately every $50 \mu \mathrm{m}$. All sections were stained with haematoxylin and eosin. Sections were examined for regression of corpora albicantia (CL of the previous pregnancy), the formation of new CL and for treatment effects on the patterns of follicular development. In the observations on follicular development, all follicles of $>150 \mu \mathrm{m}$ in diameter were counted and the numbers of follicles within discrete size ranges were assessed; counts of follicles of $>1000 \mu \mathrm{m}$ in diameter included any CL formed as a result of postpartum ovulations.

Table 1. Mating response following parturition in does

\begin{tabular}{|c|c|c|c|c|c|c|c|c|}
\hline & & \multicolumn{7}{|c|}{ Day tested post partum } \\
\hline & & 0 & 3 & 6 & 9 & 12 & 21 & 30 \\
\hline DB & $\begin{array}{l}\text { No. tested } \\
\text { No. mating }\end{array}$ & $\begin{array}{l}6 \\
6\end{array}$ & $\begin{array}{l}21 \\
20\end{array}$ & $\begin{array}{l}23 \\
20\end{array}$ & $\begin{array}{l}24 \\
20\end{array}$ & $\begin{array}{l}23 \\
20\end{array}$ & $\begin{array}{l}24 \\
20\end{array}$ & 一 \\
\hline LA-S & $\begin{array}{l}\text { No. tested } \\
\text { No. mating }\end{array}$ & 二 & $\begin{array}{l}10 \\
10\end{array}$ & $\begin{array}{l}10 \\
10\end{array}$ & $\begin{array}{l}10 \\
10\end{array}$ & $\begin{array}{l}12 \\
10\end{array}$ & 二 & $\begin{array}{l}10 \\
10\end{array}$ \\
\hline LA-NS & $\begin{array}{l}\text { No. tested } \\
\text { No. mating }\end{array}$ & - & $\begin{array}{l}10 \\
10\end{array}$ & $\begin{array}{l}10 \\
10\end{array}$ & $\begin{array}{l}13 \\
10\end{array}$ & $\begin{array}{l}13 \\
10\end{array}$ & - & $\begin{array}{l}10 \\
10\end{array}$ \\
\hline $\begin{array}{l}\text { Total S and NS } \\
\text { does tested }\end{array}$ & $\begin{array}{l}\text { Post-partum } \\
\text { Control }\end{array}$ & \multicolumn{7}{|c|}{179} \\
\hline $\begin{array}{l}\text { Total S and NS } \\
\text { does mating }\end{array}$ & $\begin{array}{l}\text { Post-partum } \\
\text { Control }\end{array}$ & \multicolumn{7}{|c|}{160} \\
\hline
\end{tabular}

DB-Dutch Belted, LA-Large Albino, S-suckling, NS-non-suckling.

\section{RESULTS}

\section{Sexual behaviour}

The frequency of acceptance of the buck (mating response) is summarized in Table 1. In the first experiment, there was no significant effect of time of testing post partum on the mating response. A similar lack of effect of time to mating was found for both suckling and non-suckling does in the second experiment; suckling also had no significant effect on mating response in the LA does.

\section{Ovulation}

The extent of induced ovulation following mating is shown in Text-fig. 1 . The differences for DB does between the total failure of ovulation in Day-0 animals and the ovulation responses in the Day-12 and Day-21 groups were statistically significant $(P<0.001)$; as were also the differences in mating responses at Day 3 compared to matings at Day 12 and Day $21(P<0 \cdot 05)$.

The extent to which ovulation was induced in the LA does after mating was 
not significantly affected by the time to mating. It was found, however, that significantly fewer suckling does ovulated following mating compared to the non-suckling animals $(P<0.01)$.

When the mean ovulation rate (the number of ovulations/doe) was considered for those LA does that had ovulated, it was found that the mean ovulation rate in suckling does $(10 \cdot 18 \pm 0.29)$ was significantly greater $(P<0.01)$ than that in the non-suckling animals $(8 \cdot 91 \pm 0 \cdot 29)$.

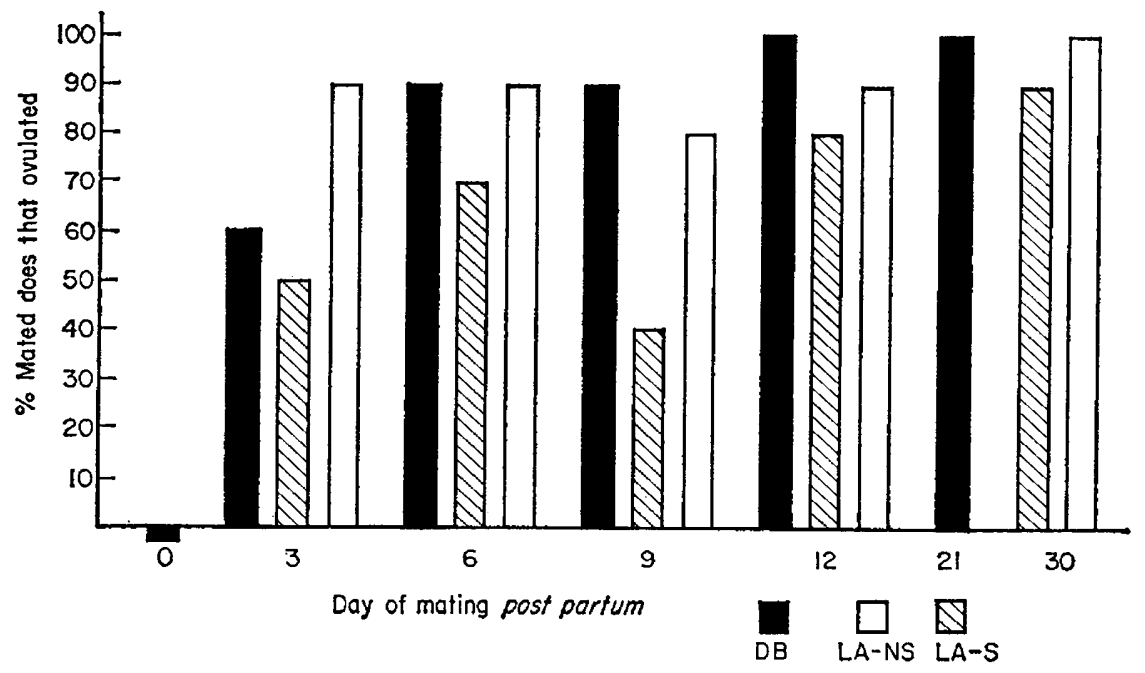

Text-FIG. 1. The incidence of induced ovulation following post-partum matings in Dutch Belted (DB) and Large Albino (LA) rabbits. S-suckling, NS-non-suckling.

Table 2. Fertilization of ova from post-partum matings of does

\begin{tabular}{ll|rrrrrr}
\hline & & \multicolumn{6}{|c}{ Day mated post partum } \\
& & 3 & 6 & 9 & 12 & 21 & 30 \\
\hline Percentage of & DB & 77 & 75 & 87 & 85 & 100 & - \\
recovered ova & LA-S & 98 & 84 & 100 & 98 & - & 95 \\
fertilized & LA-NS & 93 & 100 & 100 & 100 & - & 89 \\
\hline
\end{tabular}

DB-Dutch Belted, LA-Large Albino, S-suckling, NS-nonsuckling.

\section{Fertilization of ova}

Fertilization rates, expressed as percentage fertilization of all ova recovered/ group, are shown in Table 2. In the Dutch Belted rabbits, the fertilization rate in does mated on Day 21 post partum was significantly higher than that in does mated on Days 3,6 or $9(P<0.01)$ and on Day 12 post partum $(P<0.05)$.

Observations on ova recovered from LA does revealed no significant treatment effects on fertilization rate. 


\section{Uterine involution}

Uterine involution expressed as a change in weight with time after parturition is shown in Text-fig. 2, uteri being examined 2 days post coitum.

The pattern of involution for LA does was consistent for both suckling and non-suckling animals. No effect of suckling on uterine weight was apparent in uteri examined on Day 5 post partum, but comparison of uterine weights for the suckling and non-suckling does in which uteri were examined on Days 8, 11, 14 and 32 revealed a highly significant effect of suckling, increasing involution $(P<0.001)$; maximal involution for all does being observed on Day 11 post partum.

The pattern of involution in the DB rabbits was similar to that in the LA does but the overall changes in weight were proportionately smaller. Maximal involution in these does was also recorded at Day 11.

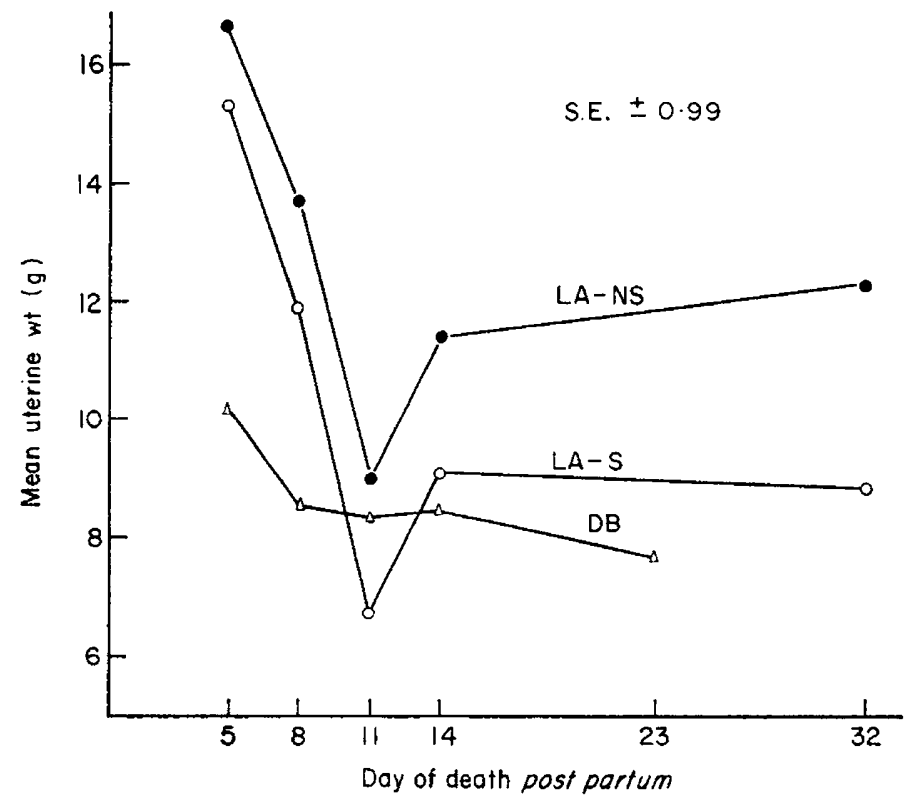

TexT-FIG. 2. Uterine involution in Large Albino (LA) and Dutch Belted (DB) does after parturition. S-suckling, NS-non-suckling.

Histological examination of uterine sections showed that decreases in both endometrial and myometrial tissues contributed to the overall decrease in uterine weight. A subjective assessment was also made of the glandular development in the endometrium of the LA does killed 2 days post coitum. A considerable range of development was observed, from the almost total absence of any uterine glands to uteri where the endometrium was largely composed of glandular tissue. Overall assessments for each group suggested that the endometrial development for both suckling and non-suckling does at Day 11 post partum was below that at other times. In all but the Day-11 groups, the endometrial glands of the suckling groups seemed better developed than those of the non-suckling animals. 
Ovarian histology

The patterns of change in ovarian weight with time after parturition are shown in Text-fig. 3, again recorded 2 days post coitum.

In LA does, a consistent pattern of change for both suckling and non-suckling animals was established, with a maximal decrease in weight apparent at Day 11 post partum. In contrast to the effects on uterine involution, no significant effect of suckling was found for ovarian changes post partum.

The mean ovarian weights for DB rabbits do not appear to represent any comparable pattern of involution. Considerable within-group variation in ovarian weights occurred in this experiment and may have obscured the usual pattern of change in these animals.

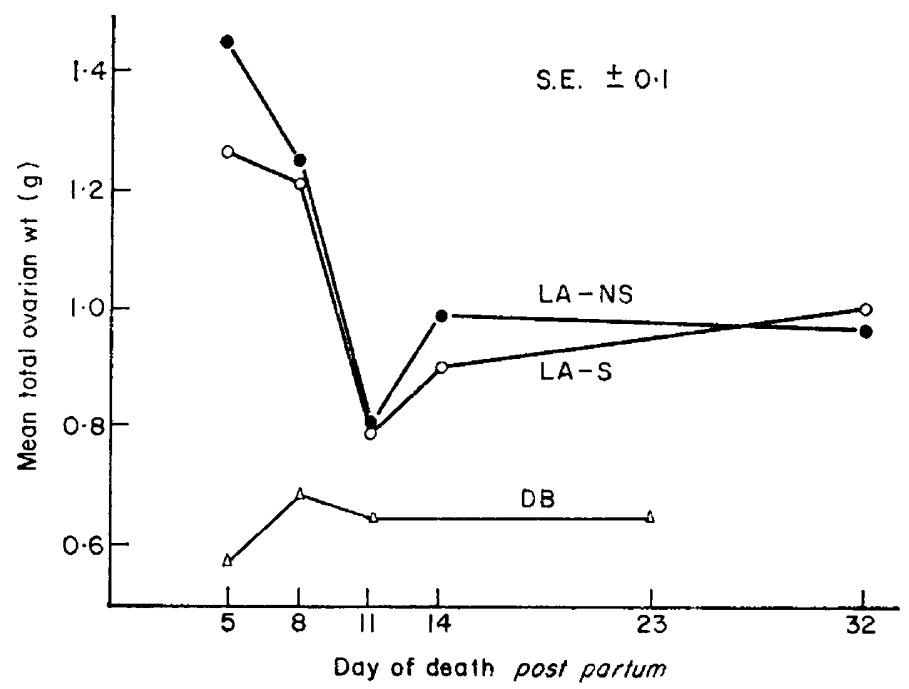

TExT-FIG. 3. Ovarian involution in Large Albino (LA) and Dutch Belted (DB) does after parturition. S-suckling, NS-non-suckling.

\section{Regression of corpora albicantia}

Measurement of the mean diameter of corpora albicantia in the ovaries of all does killed on Day 5 and Day 11 post partum demonstrated no overall effect of suckling on the regression of corpora albicantia. Although regression increased with time post partum, it did not appear to follow a consistent pattern. An initial decrease in mean diameter was found from $1.81 \pm 0.02 \mathrm{~mm}$ in all does killed on Day 5 to $1.50 \pm 0.04 \mathrm{~mm}$ measured at Day 8 in the suckling group of does, and this decrease was significant $(P<0 \cdot 001)$. Following this initial decrease, no further change was observed in the diameter of corpora albicantia by Day 14 post partum. Although precise measurement of corpora albicantia was difficult in the control suckling group at Day 32, where measurements were possible, a mean of $1.11 \mathrm{~mm}$ indicated that considerable regression had occurred after Day 14 post partum.

\section{Follicular development}

The total numbers of follicles counted with a diameter of $>150 \mu \mathrm{m}$ and the 
numbers of follicles within discrete size ranges are shown for each group counted in Text-fig. 4. The numbers of follicles in each size range are expressed as a percentage of the total follicular count for that group.

On the basis of total follicular counts, there was a depression in the numbers of follicles present with increased time after parturition, and comparisons between the numbers of follicles at Day 5 and Day 11 post partum for both suckling and non-suckling animals showed significant decreases in follicular development by Day 11 post partum $(P<0.001$ and $P<0.05$ for suckling and non-suckling does, respectively). A similar significant depression in follicular development, compared to that at Day 5, was also established at Day 14 post partum $(P<0.001)$.

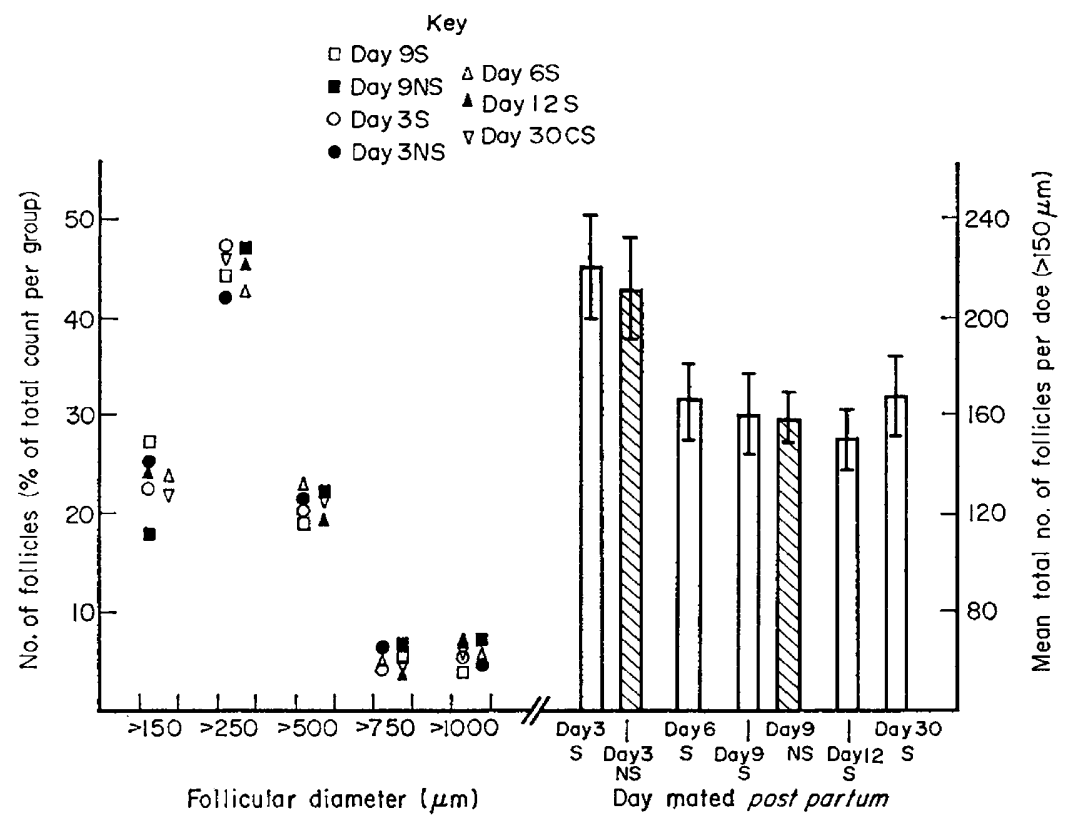

TEXT-FIG. 4. The development of ovarian follicles in Large Albino rabbits after parturition. $\mathrm{S}-$ suckling, NS-non-suckling, C-control.

Follicular development at Day 5 post partum compared to that in the control suckling group at Day 30 suggested that enhanced follicular development occurred soon after parturition compared to that in control weaning animals.

Having established a decrease in follicular development following parturition, the proportional distribution of follicles of different sizes in each group was of interest and in all groups counted, the proportional distribution was very similar. Thus, any decrease in follicular development post partum appears to affect equally all stages of follicular development from antral formation onwards rather than affecting any particular phase of follicular maturation.

Considerable failure of induced ovulation was found in the Day-3 suckling and Day-9 suckling groups of does. A comparison of the mean numbers of large follicles ( $>\mathrm{I} \mathrm{mm}$ in diameter) present in the ovaries of does that failed to 
ovulate in these groups revealed a significant difference between a mean of $8 \cdot 8 \pm 1 \cdot 16$ follicles/doe in the Day-3 suckling group and $3 \cdot 2 \pm 1 \cdot 25$ follicles/doe in the Day-9 suckling group $(P<0 \cdot 01)$. A significant decrease in the number of large follicles due to suckling was also found in the Day-9 suckling compared to the Day-9 non-suckling group of animals $(P<0.05)$.

\section{Formation of corpora lutea}

The mean diameter of newly formed CL measured 2 days post coitum was determined for those does that ovulated, in the groups in which ovarian histology was studied. Increased time to mating after parturition resulted in the formation of significantly smaller CL; the mean diameter for the Day-3 suckling does $(1.48 \pm 0.05 \mathrm{~mm})$ being greater than that for the suckling groups mated on Day $6(1.27 \pm 0.01 \mathrm{~mm})$, Day $9(1.22 \pm 0.02 \mathrm{~mm})$ and Day $12(1.23 \pm 0.01 \mathrm{~mm})$ after parturition $(P<0.001)$. A further significant decrease occurred between the Day-6 and Day-12 groups of suckling does $(P<0 \cdot 05)$. A similar decrease in CL size was found between the Day-3 $(1.31 \pm 0.03)$ and Day-9 $(1 \cdot 18 \pm 0.01)$ mated non-suckling does $(P<0.001)$. Furthermore, the mean diameter of CL formed in the control group of suckling does was consistently smaller $(1 \cdot 11 \pm 0.01$ $\mathrm{mm})$ than that in any of the groups mated soon after parturition $(P<0.001)$. No consistent effect of suckling on CL size was found, however, compared to non-suckling does, where comparison was possible for animals mated on Day 3 or Day 9.

\section{DISCUSSION}

There appears to be a high potential fertility in the domestic rabbit in the early period after parturition, compared to other domestic species. Although somewhat variable, the overall fertility of the suckling animals in these experiments showed marked improvement on the earlier results reported by Hammond (1925). The reasons for this improvement may relate to better management conditions, especially in terms of nutrition, as demonstrated by Adams (1967).

The time of mating following parturition appeared to have a more profound effect on the patterns of behaviour and fertility studied than did the presence or absence of suckling. These effects of time post partum produced consistent patterns of change in both suckling and non-suckling animals. Any effects of suckling tended to accentuate such time-based changes and, in certain specific cases, proved critical with respect to the level of fertility resulting.

The patterns of uterine involution clearly illustrate the comparative effects of time post partum and suckling, the changes confirming the reports of earlier workers (Hammond, 1925; Bull, 1949). In the case of ovarian change, little effect of suckling was found. Histological examination of the ovaries of the LA does demonstrated that ovarian involution was attributable both to a rapid regression of the CL of the previous pregnancy (corpora albicantia) and to a decrease in follicular development.

Although suckling alone significantly reduced the ovulation response to mating in the LA does, there again appeared to be an underlying effect of time: in the case of the DB does, this effect was significantly established. The low levels of induced ovulation in the suckled does soon after parturition in the 
present studies suggest that the failure to establish pregnancy reported by Beyer \& Rivaud (1969) in a large proportion of does mated during the post-partum oestrus may have been due to ovulation failure rather than to the embryonic mortality suggested by these authors.

The decrease in total follicular development following parturition suggests that a decrease in pituitary gonadotrophin output occurs at this time. Furthermore, the high level of follicular development at Day 5 post partum compared to that in the control group, although non-significant, indicates that a peak of follicular development may exist soon after parturition. This, in turn, suggests that the extended post-partum oestrus found in the rabbit may have its origin in a considerable increase in the output of follicular oestrogens in the early period after parturition. Declines in follicular development from this original peak level would then result in a decrease in follicular oestrogens and, thus, in a decrease of their demonstrated luteotrophic effect (Keyes \& Nalbandov, 1967): the decrease in size of CL formed, with increased time to mating after parturition, could thus be explained on the basis of a decrease in follicular oestrogen, although the smaller size of CL formed in the control suckling group could not be explained in this way. The results of Adams (1967) suggest that the decrease in luteal size may possibly indicate initial luteal regression in the animals ovulating in the post-partum period, similar to that observed in does in which the FSH stimulation of follicular development was depressed due to restricted nutrient intake.

The marked reduction in induced ovulation in the Day-9 suckling group of does was paralleled by a significant reduction in the number of large follicles compared to the Day-9 non-suckling animals, in which the level of ovulation was high. Suckling acts to accentuate the depression in follicular development already present at Day 11 to the point where insufficient large follicles were present to permit ovulation to occur.

In contrast to the Day-9 group, the failure of ovulation in the Day-3 suckling group cannot be explained in terms of poor follicular development, and this could equally apply to the poor ovulation found at Day 0 and Day 3 in the DB does, although detailed examinations were not made of the ovaries of these animals. Support for this conclusion comes from the work of Adams (1968) in which a group of does induced to ovulate following HCG injections within $24 \mathrm{hr}$ of parturition was found to have a mean of $10.2 \mathrm{CL} /$ doe, confirming that adequate follicular development was present for normal ovulation to occur soon after parturition. The cause of ovulation failure in these groups may be due to low secretion or release of LH. Alternatively, there may be a block to the normal neural response to copulation, although in view of the high levels of induced ovulation in the Day-3 non-suckling group of does, any immediate after-effects of parturition itself would not appear to be responsible for such a blockage.

Irrespective of such variations in ovarian function, it was found that at least a proportion of does in all but the Day- 0 group had ovulated in response to mating. Hence, ovarian function does not constitute an absolute block to concurrent lactation and pregnancy as has been found in other species (e.g. the pig). Having established that the involuting uterus is able to support normal transport of spermatozoa, investigations are at present in progress to determine 
the extent to which the uterus is able to support implantation and fetal development after mating during the early post-partum period.

Variability in some of the results between the different strains of does used in these studies may relate to the difference in parity of the animals. It was possible, however, that this variability reflected inherent differences in the fertility of the Dutch Belted and Large Albino does in the post-partum period.

\section{ACKNOWLEDGMENTS}

We wish to acknowledge financial support from the Ministry of Agriculture, Fisheries and Food (G.R.F.) and from the British Council (H.H.) received during the course of this work.

\section{REFERENCES}

ADams, G. E. (1967) Concurrent lactation and pregnancy in the rabbit. F. Reprod. Fert. 14, 351.

ADAMs, G. E. (1968) Ovarian response to human chorionic gonadotrophin and egg transport in the pregnant and post-parturient rabbit. 7. Endocr. 40, 101.

BEYER, C. \& RIVAUd, N. (1969) Sexual behaviour in pregnant and lactating domestic rabbits. Physiol. E Behav. 4, 753.

Breed, W. G. \& Hulliard, J. (1970) Effect of lactation on ovarian function in the rabbit. F. Reprod. Fert. 23, 73.

BuLI, M. M. (1949) Repair of the placental site in the rabbit. F. Obstet. Gynaec. Br. Emp. 56, 799.

HAMmond, J. (1925) Reproduction in the rabbit. Oliver \& Boyd, London.

Harned, M. A. \& CAsida, L. E. (1969) Some postpartum reproductive phenomena in the domestic rabbit. F. Anim. Sci. 28, 785.

Keyes, P. L. \& Nalbandov, A. V. (1967) Maintenance and function of corpora lutea in rabbits depend on estrogen. Endocrinology, 80, 938.

Yaschine, Y., MENA, F. \& Beyer, G. (1967) Gonadal hormones and mounting behaviour in the female rabbit. Am. F. Physiol. 213, 867. 